\title{
THE TYRANNY OF THE IDENTITY: GROWTH ACCOUNTING REVISITED
}

\author{
Jesus Felipe \\ Economics and Research Department \\ Asian Development Bank \\ Manila (Philippines) \\ e-mail: jfelipe@adb.org
}

\author{
JSL McCombie \\ Centre for Economic and Public Policy \\ Department of Land Economy \\ University of Cambridge \\ Cambridge (UK) \\ e-mail: jslm2@hermes.cam.ac.uk
}

October 21, 2005

\begin{abstract}
It has been argued in the literature that growth accounting may be undertaken by directly differentiating the national income and product accounts identity. This paper shows that this is simply an exercise in the manipulation of an accounting identity without any theoretical foundation. Simulations show that the estimates of total factor productivity growth resulting from growth accounting performed with aggregate value data are not equivalent to the true rate of technological progress implied by the micro data. It is concluded that the rate of total factor productivity growth, as usually estimated, is simply a measure of changes in distributional income.
\end{abstract}

JEL Classification: O11, O16, O47, O53 


\section{INTRODUCTION ${ }^{1}$}

A number of papers (Barro 1999; Hsieh 1999, 2002) have argued that the neoclassical growth accounting exercises, specifically the derivation of the dual measure of total factor productivity growth (TFPG), can be performed by simply differentiating the National Income and Product Accounts (NIPA) identity. The identity is $V_{t} \equiv w_{t} L_{t}+r_{t} J_{t}$, where $V$ is value added, $w$ is the average wage, $L$ is employment, $r$ is the rate of profit and $J$ is the value of the capital stock. The monetary variables are all measured in real terms. $^{2}$

This approach to growth accounting stands in marked contrast to the arguments of Felipe and McCombie (2003). There it was argued that precisely because of the existence of the accounting identity, growth accounting exercises amount to no more than manipulations of the ex-post national income accounting identity, and, as such, they are tautologies without necessarily any behavioral content. The reason for the problem that Felipe and McCombie (2003) highlight is that there is an important difference between using physical data, only available at a disaggregated level and which should theoretically be used in growth accounting and production function studies, and data expressed in value terms. However, the latter is the form of data actually used in most growth, if not all, accounting exercises.

This paper has two purposes. The first one is to provide a critical evaluation of what superficially seems to be a useful methodological procedure; that is, to derive the rate of TFPG from the NIPA, as suggested by Barro and Hsieh. The second purpose is to consider, by using a simulation exercise, whether or not the rate of total factor

\footnotetext{
${ }^{1}$ We are grateful to Rana Hasan, Franklin M. Fisher and the participants at the conference on "Understanding Economic Growth: New Directions in Theory and Policy", Cambridge, U.K., September 1-3, 2005, for their comments and suggestions. The usual disclaimer applies. This paper represents the views of the authors and does not represent those of the Asian Development Bank, its Executive Directors, or the countries that they represent.

${ }^{2}$ The national accounts only give data for total wages $(W)$ and total profits $(\Pi)$ but employment and capital stocks (calculated using the perpetual inventory method) are readily available from many statistical sources such as the OECD, the US Bureau of Labour Statistics, etc.
} 
productivity growth (TFPG) using aggregate data (in value terms) is always a reasonable approximation to the true rate of technical progress calculated using disaggregated data (in physical terms). We find, in fact, that the two values can differ markedly. We conclude that the growth accounting approach as presently carried out in most cases may give very misleading estimates of technical change.

\section{THE NIPA AND GROWTH ACCOUNTING}

The Barro-Hsieh thesis is that growth accounting exercises can be directly performed using data from the NIPA, according to which value added equals the payments to the factors of production,

$$
V_{t} \equiv w_{t} L_{t}+r_{t} J_{t}
$$

without any other assumptions. For example, Hsieh (2002, p.505) is of the opinion that "with only the condition that output equals factor incomes, we have the result that the primal and dual measures of the Solow residual are equal. No other assumptions are needed for this result: we do not need any assumption about the form of the production function, bias of technological change, or relationship between factor prices and their social marginal products.” Barro (1999, p.123) concurs: "the dual approach can be derived readily from the equality between output and factor income”. To show this, he writes the income accounting identity, differentiates it, and expresses it in terms of growth rates (Barro 1999, equations (7) and (8), p. 123). Barro and Hsieh agree that, in Barro's words, “it is important to recognize that the derivation of equation (8) [the growth accounting equation in Barro's paper] uses only the condition $V_{t}=r_{t} J_{t}+w_{t} L_{t}$. No assumptions were made about the relations of factor prices to social marginal products or about the form of the production function” (Barro 1999, pp.123). ${ }^{3}$ Barro continues: "If the condition $V_{t}=r_{t} J_{t}+w_{t} L_{t}$ holds, then the primal and dual estimates of TFP growth inevitably coincide [...] If the condition $V_{t}=w_{t} L_{t}+r_{t} J_{t}$ holds, then

3 The notation in Barro's quotations has been changed to make it consistent with that in this paper. 
the discrepancy between the primal and dual estimates of TFP has to reflect the use of different data in the two calculations” (Barro 1999, p.123-4).

Alternatively, from our point of view, it is important to emphasize that the symbol "”” in the equation for value added indicates that it is an accounting identity, which has, per se, no behavioral implications and will hold irrespective of the state of competition and whether or not an aggregate production function actually exists.

Why do Hsieh and Barro argue that growth accounting can be undertaken by simply manipulating the NIPA identity? The answer is that if equation (1) is differentiated, the following is obtained:

$$
\hat{V}_{t} \equiv a_{t} \hat{w}_{t}+\left(1-a_{t}\right) \hat{r}_{t}+a_{t} \hat{L}_{t}+\left(1-a_{t}\right) \hat{J}_{t}
$$

where $\wedge$ denotes a proportional growth rate, $a_{t} \equiv w_{t} L_{t} / V_{t}$ is the share of labor in output, $\left(1-a_{t}\right) \equiv r_{t} J_{t} / V_{t}$ is the share of capital. Equation (2) can be rearranged to give:

$$
\begin{aligned}
T F P G_{t} & \equiv \hat{V}_{t}-\left(1-a_{t}\right) \hat{J}_{t}-a_{t} \hat{L}_{t} \\
& \equiv a_{t} \hat{w}_{t}+\left(1-a_{t}\right) \hat{r}_{t}
\end{aligned}
$$

where TFPG is interpreted as the rate of total factor productivity growth.

Equations (3a) and (3b), under the usual neoclassical assumptions, are formally equivalent to the growth accounting residual measure of total TFPG. These assumptions include the existence of a well-behaved aggregate production function; perfectly competitive markets and the marginal productivity theory of factor pricing. Indeed, it may be shown that the first order conditions from differentiating the production function will, through Euler's theorem, ensure that the accounting identity holds. A result is that the factor shares will equal the corresponding output elasticities, so we have: 


$$
\hat{V}_{t}=T F P G_{t}+\alpha_{t} \hat{L}_{t}+\beta_{t} \hat{J}_{t}
$$

where $\alpha_{t}=a_{t}$ and $\beta_{t}=\left(1-a_{t}\right)$ and TFPG is the Solow residual

The underlying assumptions, however, are not innocuous.. The interpretation of $\mathrm{TFPG}_{t}$ in equations (2) and (3a) and (3b) as the rate of technological progress follows directly from a comparison with (4); otherwise, there are no grounds for referring to $T F P G_{t}$ in equations (2) and (3a) and (3b) as the rate of technical progress. In fact, it has been argued that the aggregate production function, through the usual neoclassical assumptions and Euler's theorem provides a theory of the income side of the NIPA (Hulten 2001, p.11, Prescott 1998, p.532. See also Jorgenson and Griliches, 1967, p.252-3). The theory implies that given an aggregate production $V=f(L, J, t)$ the following equation holds: $V=f_{L} L+f_{J} J$. From the first-order conditions $f_{L}=(\partial F / \partial L)=w$ and $f_{J}=(\partial F / \partial J)=v$, it follows that $V=w L+v J$, (where $v$ is the rental price of capital) which is taken to be the identity (1). The neoclassical framework considers that the production function, through Euler's theorem, implies the identity, But the important thing to note is that under this argument, this identity has become a "virtual" identity, and the interpretation of TFPG in equations (3a) and 3(b) as a measure of technical progress, or the growth of output not explained by the growth of factor inputs, holds if and only if the theory under which it was built holds.

On the other hand, our argument is that the wage bill and total profits can be split into the respective products (i.e., equation (1)) without recourse to any theory and do not require that wage and profit rates equal their respective marginal products. Our argument (Felipe and McCombie, 2003) ${ }^{4}$ is that the identity $V \equiv W+\Pi \equiv w L+r J$ holds irrespective of whether or not any of these conditions are fulfilled. Hsieh's quotation cited above that "we do not need any assumption about the form of the production function, bias of technological change, or relationship between factor prices

${ }^{4}$ This criticism in a very sketchy form, can be traced back to the Reder (1943). Important more recent expositions include Phelps Brown (1957), Shaikh (1980), and Simon (1979). 
and their social marginal products" is misleading to the extent that it could be interpreted as implying that none of these conditions are required for growth accounting. What it simply means is that if we have an identity $X \equiv Y+Z$, then this may be expressed as $\hat{Y} \equiv(1 / \theta) \hat{X}-((1-\theta) / \theta) \hat{Z}$ where $\theta \equiv Y / X$. If we term the righthand side the "primal", then by definition it must equal the left-hand side, whether it is called the "dual" or anything else. Therefore, any measurement error on either the right-hand side or the left-hand side of the equation in growth rate form must lead to an equal error on the opposite side. But this should not lead to overlook the necessary assumptions that underlie the growth accounting approach, if either the dual or the primal is to be interpreted as a measure of technical progress, or of the increase in efficiency.

Consequently, bearing this qualification in mind, from the accounting identity, if a consistent data set (i.e., one that makes the identity (1) hold) is used for calculating the dual and the primal measures of TFPG, then, by definition, they must be equal. The identity consists of five variables, namely, $V, w, L, r$, and $J$. If values of each are obtained "independently" then it is possible that the identity, equation (1), will not hold because of measurement error. For this reason, to ensure consistency, one of the variables must be obtained residually. Normally, the ex post rate of profit is the variable that is calculated residually as $r_{t} \equiv\left(V_{t}-w_{t} L_{t}\right) / J_{t}{ }^{5}$

It is important to mention that, in his calculations, Hsieh did not use the accounting identity exactly as described above. Instead of calculating $r$ residually, he computed the rental price of capital $(v)$ as $v_{t}=q_{t}\left[\rho_{t}+\delta_{t}-\dot{q}_{t}\right]$ (Jorgenson 1963) where $q$ is the price of capital, $\rho$ is a measure of the cost of capital, $\delta$ is the depreciation rate and $\dot{q}$ is the capital gain or loss. If this is used in the identity with the other variables independently measured, then there may be a statistical or measurement problem along the lines outlined above. Nevertheless, in Felipe and McCombie (2006a,

\footnotetext{
${ }^{5}$ Alternatively, the values of one or more of the variables must be adjusted to ensure that the identity holds.
} 
2006b) we show that this issue does not pose a conceptual problem for our argument. In this case, value added should be adjusted to ensure that the identity holds.

A different approach by Hart (1996) would initially seem to agree with our augments; but there are significant differences. He starts from the accounting identity and correctly emphasizes that "accounting identities, unlike the usual econometric estimates of production functions, hold in equilibrium and in disequilibrium” (Hart 1996, p.226). He views the identity as representing the trading accounts of the representative firm, but because of data limitations, he uses macroeconomic data. However, he calculates TFPG, or multifactor productivity (MFP) growth, as he terms it, as the weighted growth of factor prices, citing in support of this the discussion of the dual by Jorgensen and Griliches (1967). Nevertheless, somewhat confusingly, he argues that the accounting identity (dual) approach makes it easier to explain the effects on MFP growth of "disequilibrium, market imperfections, trade-union cost pushes, OPEC oil-price squeezes, Government price controls and incomes policies, regulation and deregulation and of other forces which influence profit margins. It must be remembered that these dual measures of MFP are purely statistical, and, so far no use has been made of production functions, returns to scale, marginal productivity, competitive equilibrium conditions or any economic theory of production” (Hart 1996, p.228).

What is the justification for using factor shares as weights for the growth of the factor inputs, as Hart does? The standard justification rests solely on the argument that they are a good approximation to the output elasticities. However, this requires standard neoclassical production theory. Hart (1996, p.229) gives an example where an increase in $V$ goes entirely to labour due to trade union bargaining: "so the direction of causation is from left to right”, i.e. from the increase in $V$ to the increase in $w$. This means that that the share of wages increases, but, we would argue, this might have nothing to do with changes in the output elasticity of labour or in the technical 
conditions of production. ${ }^{6}$ Thus, the shares could merely reflect the bargaining power of labor and capital and, as we have argued above, can change without there necessarily being any change in the technical conditions of production. Hence, in this case the shares cannot be taken as reflecting the aggregate output elasticities, even if these exist.

To discuss the decomposition of output growth in any "meaningful” way into TFPG and the contribution of the growth of factor inputs does require aggregate production theory, pace Hart. This is true whether we measure TFPG in terms of the weighted growth of factor prices or in terms of the growth of output minus the weighted growth of factor inputs. Indeed, the two methods will, as we have seen, give identical results if $r$ (or $J$ ) is calculated residually (as Hart does). Any differences will be purely statistical due to different data sources, etc. Indeed, Hart's empirical analysis comes largely to this conclusion and ironically his method, if not his interpretation, would be the same procedure as that adopted by a neoclassical growth accountant working from the dual.

Hart (1996) also argues that when one uses gross output and double deflation, the identity no longer holds. "Instead we write $Y=f(L, M, K)$ and we use production theory” (Hart 1996, p.229), where $Y$ is gross output and $M$ is materials. It is difficult to see any justification for this, as one needs to construct an implicit deflator for wages and profits and this should (must) preserve the identity in real terms. Hart concedes that analysis using the production function also has to use deflated values "so the problems created by relative changes in output and input prices are still present” (Hart 1996, p. 229). So, according to this argument, an index number problem necessitates a particular theory, which is then subject to the same problem. Index number problems do present problems for quantitative analysis but they are only of second-order importance in this context

$6 \quad$ Hart suggests that this may possibly be due to a reorganization of labor agreed to by the unions. To the extent that this leads to increased efficiency and output, then the causation could be said to run from right to left. 
Finally, it should be noted that estimates of TFPG have recently been calculated using physical data for output at the seven-digit SIC product classification (Foster, et al. 2005). An example of this type of output is ready-mixed concrete or boxes. However, this approach does not avoid our strictures, as inputs are still measured in value terms and the weights are the cost shares. Thus, total factor productivity growth in value terms is given by

$$
T F P G_{i t}=\left(\hat{Q}_{i t}+\hat{p}_{i t}\right)-a_{L_{i t}} \hat{L}_{i t}-a_{J_{i t}} \hat{J}_{i t}-a_{M_{i t}} \hat{M}_{i t}-a_{E_{i t}} \hat{E}_{i t}
$$

where $\hat{Q}$ is the growth of firm i's physical output, $\hat{p}_{i t}$ is the rate of change of firm $i$ 's relative price and $\hat{M}$ and $\hat{E}$ are the growth rates of materials and energy. The $a$ 's are the relevant factor shares. The growth of "physical" total factor productivity is given by $T F P G_{Q_{i t}}=T F P G_{i t}-\hat{p}_{i t}$. While this approach has the advantage of removing from the estimate of total factor productivity growth fluctuations in a firm's relative price due to, for example, "idiosyncratic" demand shocks, it can be seen that the contribution to output growth of the inputs is still calculated using value data.

Before concluding this section, it is worth noting that, as indicated above, a crucial assumption underlying this whole approach is that a well-behaved aggregate production function exists, which should theoretically be estimated using physical quantities. This is taken to be self-evident and is rarely, if ever, explicitly discussed. However, this is not an innocuous assumption and indeed there are two theoretical reasons for believing that the aggregate production function cannot exist. The first stems from the results of the Cambridge Capital Theory Controversies, which seem to be long forgotten and rarely mentioned in the literature. Nevertheless, however inconvenient for the aggregate neoclassical approach, these results still stand. See, for example, the recent retrospective view by Cohen and Harcourt (2003). Secondly, there are the equally, if not more, damaging aggregation problems, recently surveyed by Felipe and Fisher (2003). 
Suffice to say here that both these critiques addressed, from very different points of view, the question of whether or not the aggregate production function, with the usual neoclassical properties, is a legitimate concept, even when viewed as an approximation. Both criticisms come to the same conclusion on this point: the existence -and hence the use- of aggregate production functions is very problematic. This implies that the connection made in neoclassical macroeconomics between the identity, the aggregate production function and Euler's theorem is very tenuous, to say the least. Indeed, this line of reasoning is untenable if the aggregate production function does not exist; ${ }^{7}$ and as Fisher pointed out, "If aggregate capital does not exist, then of course one cannot believe in the marginal productivity of aggregate capital” (Fisher 1971a, p.405; italics in the original).

Why is then the aggregate production function still so widely used? The answer, although it is rarely explicitly stated, must be that ever since the early estimations of Douglas and his colleagues, the statistical estimation of aggregate production functions gives good fits with the estimates of the output elasticities close to the observed factor shares, although time-series results are known for their fragility (see Sylos-Labini 1995; see Felipe and Fisher 2003 for a detailed discussion). This argument relies on Friedman's (1953) instrumental methodological justification that what matters are the successful predictions of a theory, regardless of the unrealism of the underlying assumptions. Not only is this view no longer widely held by philosophers of science, but our argument shows that this justification is flawed, even on its own terms (McCombie 1998a).

$7 \quad$ As a consequence, parameters such as the elasticity of substitution are meaningless. In the words of Fisher et al. (1977): "the elasticity of substitution in these production functions is an "estimate" of nothing; there is no true aggregate parameter to which it corresponds" (Fisher et al. 1977, p.312). 


\section{SOME SIMULATION EXPERIMENTS}

To illustrate the above arguments, we undertook some simple simulations with a view to determining what growth accounting is actually measuring. ${ }^{8}$ The key question behind the exercise is the following: if an aggregate production function does not exist, what is being measured as total factor productivity growth in exercises that use aggregate data? This question has the following implications: (i) if the answer is that it is some average of individual firms' productivities then, does the aggregate method still yield such an average? If not, why not?; and (ii) more generally, how and to what extent are we misled by the results of aggregate growth accounting?

It should be emphasized that we are not performing Monte Carlo simulations. The purpose of this exercise is merely to generate a data set whose underlying structure is known, in both physical and value terms, in order to highlight the different results that the two types of data lead to in growth accounting exercises. Monte Carlo simulations studying related issues, but answering different questions, were performed by Felipe and Holz (2001). See also Fisher (1971b) and Shaikh (1980).

Table 1 summarizes the characteristics of the simulations. We assume that there are well-defined micro-production functions, which are specified in physical terms, as ideally they should be. The constant price value of output was calculated through a mark-up and the value of total profits was generated residually through the NIPA identity, i.e., equation (1). It is assumed that each firm produces a homogenous output, which may or may not be the same for all firms. The analysis does not depend on this assumption so long as, in the former case, it is not possible to recover the physical quantities from the value data. In the latter case, i.e., output is not homogeneous across firms, we cannot, of course, estimate a cross-section production function using physical data. It is important to emphasize that we generate two types of data, in physical terms and in value terms. The former are assumed and generated so as

\footnotetext{
${ }^{8}$ These results extend an earlier simulation based on time-series data (McCombie, 2001).
} 
to give a good fit to the Cobb-Douglas function. The investigator does not know this. Value data, as indicated above, are generated through the accounting identity. The investigator knows all the value data but cannot recover the physical data from them.

It should also be noted that in the case where a cross-firm production function is estimated, no aggregation problem à la Fisher is involved if we assume all firms produce the same output and the firm is the unit of observation. This is an important point. If we need to estimate a production function using outputs and inputs summed over different firms, we encounter all the well-known aggregation problems. As value data has to be used in estimating this aggregate production function, we can explain why regressions using these data give a good fit to the aggregate data when theoretically they should not (Fisher, 1971b, Felipe and McCombie, 2005c). But the problem is even more fundamental than this. As will be demonstrated, the accounting identity presents insurmountable problems of interpretation, even when there are no aggregation problems of any kind regarding functional forms, or affecting output, labor or capital (see Felipe and Fisher 2003) or problems of the type discussed in the context of the Cambridge debates regarding the nature and construction of capital stocks (Cohen and Harcourt 2003).

The important aspect of our simulations is that they show how the use of value data can give results at variance with the true magnitudes of the underlying production functions and, therefore, misleading numerical estimates of both the parameters of the production function and of the "rate of technical progress." For clarity, we will confine the term "technical progress" to that calculated using physical data; and the term "total factor productivity” to that calculated using value data. 
Table 1. Summary of the Characteristics of the Simulations

\section{Cross-Firm Estimation of the Production Function}

- There are 10 firms, one period.

- Identical production functions are of the form $Q_{i}=\left(A_{0} L_{i}\right)^{\alpha} K_{i}^{(1-\alpha)}$, where $Q_{i}$ and $K_{i}$ are generated as random variables. $L_{i}$ is calculated through the production function. These are physical data. $A_{0}$ is the same across firms and normalized to 1.

- Output elasticities are (i) labour, $\alpha=0.25$; (ii) capital, $(1-\alpha)=0.75$, with a random error to avoid multicollinearity.

- Value data: Firms set prices as a mark-up on unit labor costs, i.e., $p_{i}=(1+\mu) w_{i} L_{i} / Q_{i}$, where $\mu=0.33$ is the same across firms.

- Money wage rate is $w_{i}=w$ and is the same across firms.

- Profit rate is $r_{i}=r=0.10$ and is the same across firms.

- Output in value terms is $V_{i}=p_{i} Q_{i}$.

- Capital stock in value terms is $J_{i}=\left(V_{i}-w_{i} L_{i}\right) / r_{i}=\left(V_{i}-w L_{i}\right) / 0.1$.

- Labor share in value terms is $a_{i}=\left(w L_{i}\right) / V_{i}=1 /(1+\mu)=0.75$.

- Capital share in value terms is $\left(1-a_{i}\right)=\mu /(1+\mu)=0.25$.

- Mean of $a_{i}$ is 0.744 (range $0.698-0.795$ )

\section{Rate of technical progress and TFPG}

- Output of the 10 firms grows at different rates over the period, but $\hat{Q}_{i}=\hat{K}_{i}$

- Same rate of technical progress for all firms, $\varphi_{i}=\alpha\left(\hat{Q}_{i}-\hat{L}_{i}\right)$, assumed to be $0.5 \%=0.25\left(\hat{Q}_{i}-\hat{L}_{i}\right)$

- Growth of employment $\hat{L}_{i}=\hat{Q}_{i}-\left(\varphi_{i} / \alpha\right)$

- Output elasticities (physical terms) and average shares (value terms) are, labour, $\alpha=0.25$, $a=0.75$ and capital, $(1-\alpha)=0.75,(1-a)=0.25$.

- True rate of technical progress (firm level): $\varphi_{i}=\hat{Q}_{i}-0.25 \hat{L}_{i}-0.75 \hat{K}_{i}$

- Total factor productivity growth: $T F P G_{i}=\hat{V}_{i}-0.75 \hat{L}_{i}-0.75 \hat{J}_{i}$

\section{Increasing Returns to Scale}

- $Q, L$ and $K$ and their growth rates as above.

- Output elasticities are labour, $\alpha=0.3$, and capital, $\beta=0.9$. Degree of returns to scale $=1.2$

- Value data calculated as before and mark-up $\mu$ is also 0.33 .

- Factor shares are labour, $a=0.75$, and capital, $(1-a)=0.25$. 


\section{(i) Cross-Firm Estimation of the Production Function}

In the first example, data in physical units were generated for 10 firms for one period under the assumption that they all have identical Cobb-Douglas constant-returns-toscale production functions given by

$$
Q_{i}=\left(A_{0} L_{i}\right)^{\alpha} K_{i}^{(1-\alpha)}
$$

where $Q_{i}$ is the number of units of homogeneous output, generated as a random variable; $K_{i}$ is the number of identical machines which are specific to the particular industry, also generated as a random variable; $L_{i}$ is the level of labor input, generated through the production function; $A_{0}$ takes the same value for all firms and was normalized to unity. The parameters $\alpha$ and $(1-\alpha)$ are the output elasticities of labor and capital, respectively, and are constructed to take values of 0.250 and $0.750 .^{9}$ The output elasticities were deliberately chosen to be the converse of the factor shares found in the NIPA.

In order to generate the monetary values, each firm sets prices as a mark-up on unit labor costs, i.e.,

$$
p_{i}=(1+\mu) w_{i} L_{i} / Q_{i}
$$

The mark-up $(\mu)$ is the same for all firms and takes a value of one third, so $(1+\mu)=1.333$. The wage rate is the same across firms, the same as the profit rate $r$, which takes a value of 0.10 . The value of the capital stock was calculated residually through the accounting identity as $J_{i} \equiv\left(V_{i}-w L_{i}\right) / r$, where $V_{i}$ is value added, constructed as $V_{i}=p_{i} Q_{i}$ for each firm using equation (7). The values of the factor shares are directly calculated using these value data. Labor's share is calculated as

$9 \quad$ To prevent perfect multicollinearity, a small random variable was added to these and, where necessary, other variables used in the simulation. 
$a_{i}=\left(w L_{i}\right) / V_{i}$ and capital's share as $\left(1-a_{i}\right)$. It should also be noted that $a_{i}=1 /(1+\mu)$, and so it takes a value of 0.75 for each firm, with a small variation due to the error term added. The mean value of labor's share for the10 firms is 0.744 (with a range of 0.698-0.795.

The mean value of the capital-output ratios in value terms $\left(J_{i} / V_{i}\right)$ is 2.57 with a range of 2.24 to 3.18. These values are very close to what are observed empirically, and are the result of a roughly constant rate of profit and constant factor shares. As $J / V=(1-a) / r$, where $(1-a)$ is capital's share and, as noted above, is approximately equal to 0.25 and the profit rate is 0.10 , the capital-output ratio will not differ much from 2.50. As we are dealing with individual firms and we design the simulations, we know both the physical data and the values, as we know the prices. But let us assume that the prices are unknown to the researcher, as is usually the case, because the output and capital stocks for different firms are aggregated in the NIPA using value measures. Consequently, $V$ and $J$ (in constant prices, although since we only have one period, the distinction between current and constant prices does not arise) were taken as proxies for $Q$ and $K$.

These value data were then used to estimate a cross-firm production function. The results of the estimation are:

$$
\begin{array}{rll}
\ln V=2.867+0.750 \ln L+0.250 \ln J & \bar{R}^{2}=0.999 \\
(478.77)(136.40) & (45.41) & \text { s.e.r. }=0.0025
\end{array}
$$

This gives a remarkably close fit to the Cobb-Douglas production function, which is to be expected given the method used to construct the data. However, some of Douglas and his colleagues' early studies, which used real, as opposed to simulated, 
cross-state data, also found very close statistical fits. ${ }^{10}$ The sum of the estimated coefficients is 1.00 and this is not significantly different from unity (the value of the $t$ ratio testing this hypothesis is 0.02). With the close correspondence between the supposed "output elasticities" and factor shares calculated from the data $(0.750 ; 0.744$ and $0.250 ; 0.256$ ), it is little wonder that such results could be interpreted as providing evidence in favor of competitive markets and disproving the Marxian argument, as Douglas (1976, p.914) claimed.

This is not withstanding the fact that factors are not paid their marginal products in physical terms in our simulation data. Competition could force firms to be $x$-efficient so that firms do hire the factors of production up to the point where their physical returns equal their factor rewards in terms of the commodity produced. This would determine the optimal $L_{i} / Q_{i}$, which is used in the mark-up pricing equation. However, using value data would still give estimates of the "output elasticities” equal to $1 /(1+\mu)$ and $\mu /(1+\mu)$, respectively.

However, it should be emphasized that the estimated "output elasticities" are, of course, not the same as the "true" output elasticities of the micro production function. In other words, the true output elasticity of labor is 0.25 , but the estimate using value data is 0.75 .

The goodness of fit is dependent upon the degree of variation in the mark-up. With identical mark-ups, the fit is exact (and estimation is not possible because of

$10 \quad$ For example, Douglas (1976, p.906) reports the following results for a production function based on American cross-section studies, 1904, 1909, 1914 and 1919.

\begin{tabular}{|c|c|c|c|c|}
\hline Year & \multicolumn{2}{|l|}{$\alpha$} & $\beta$ & $\alpha+\beta$ \\
\hline 1904 & \multicolumn{2}{|c|}{$0.65(32.5)$} & $0.31(15.5)$ & 0.96 \\
\hline 1909 & \multicolumn{2}{|c|}{$0.63(31.5)$} & $0.34(17.0)$ & 0.97 \\
\hline 1914 & \multicolumn{2}{|c|}{$0.61(30.5)$} & 0.37 (18.5) & 0.98 \\
\hline 1919 & \multicolumn{2}{|c|}{$0.76(38.0)$} & 2.5) & 1.01 \\
\hline Average & $0.66(33.0)$ & $0.32(16.0)$ & 0.98 & \\
\hline
\end{tabular}

Notes: $\quad$-values in parentheses.

Total number of observations: 1490. 
perfect multicollinearity). Indeed, it is the constant mark-up that is solely responsible for generating the "spurious" Cobb-Douglas. To demonstrate this, the physical values of the three series $Q, L$ and $K$ were next generated as random numbers. $V$ and $J$ were calculated as before. The estimation yielded a very good fit to the Cobb-Douglas with the values of the "output elasticities" the same as before (the result is not reported here). This does not necessarily mean that we are postulating that that output is actually a random function of the inputs. However, when one considers the complex production processes of any modern firm, there may be some individual parts of the process subject to fixed coefficients, whereas others subject to differing elasticities of substitution, to say nothing of differences between plants in managerial and technical efficiencies. Thus, the "randomness" may simply be a reflection of the severe misspecification error inherent in specifying the micro-production function as a CobbDouglas. But the important point to note is that even in this case, where there is no well defined micro- production function, the use value added data will give the impression that there exists a well-behaved aggregate Cobb-Douglas production function.

(ii) Rate of Technological Progress and Total Factor Productivity Growth

In order to calculate the growth of total factor productivity, we need the growth rates of output, capital and labor. We assumed that output of the 10 hypothetical firms grows at different rates (we only have one single period), but, for expositional purposes only, the series were constructed such that the growth rate of the physical capital-output ratio is zero (i.e., output and capital grow at the same rate) for all firms. It was also assumed that each firm experiences the same rate of technical progress $\left(\varphi_{i}\right), 0.5 \%$ per annum, equal to $\varphi_{i}=\alpha\left(\hat{Q}_{i}-\hat{L}_{i}\right)$. This is due to the fact that the underlying production functions are Cobb-Douglas and that the growth of output equals the growth rate of capital. Hence, the growth rate of employment for each firm was constructed as $\hat{L}_{i}=\hat{Q}_{i}-\left(\varphi_{i} / \alpha\right)$, where $\varphi_{i}=0.5 \%$, as noted above. The output elasticities of labor and 
capital in physical terms are again 0.25 and 0.75 , the average value shares are 0.745 (with a range from 0.698 to 0.795 ) and 0.255 , and the aggregate shares are also 0.745 and 0.255 since each firm has the same mark-up, which means that the labor share of each firm is the same and if we aggregate over firms, the aggregate share comes to be about the same.

The rate of technical progress using the physical simulated data would be calculated by the investigator unaware of its value (although we know it by construction, 0.5\%) for each hypothetical firm separately using the standard growth accounting equation, that is,

$$
\varphi_{i} \equiv \hat{Q}_{i}-a \hat{L}_{i}-(1-a) \hat{K}_{i}
$$

where $a$ and $(1-a)$, the factor shares of labor and capital, are assumed to equal the output elasticities $\alpha$ and $(1-\alpha), 0.25$ and 0.75 , respectively.

As the rate of technical progress is the same for each firm, we can talk about the rate of technical progress being $0.5 \%$ per annum; even in the case where we assume that the physical outputs of the various firms are not homogeneous.

However, let us assume, once again, that the individual prices of the various firms are not available and so it is not possible to extract data on the physical units of output. All that can be used in empirical work, as is usually true in practice, is the constant price value of output and of the capital stock. The growth of total factor productivity is given by:

$$
T F P G_{i} \equiv \hat{V}_{i}-a \hat{L}_{i}-(1-a) \hat{J}_{i}
$$

where now the shares are 0.75 and 0.25 , respectively.

The unweighted mean rate of total factor productivity growth of the individual firms is $1.49 \%$ per annum, which, not surprisingly, is almost identical to the rate of total factor productivity growth obtained by aggregating the value data over all 10 firms and using these in equation (9) (1.48\% per annum). 
Thus, the use of physical data yields technical progress accounting, on average (the unweighted mean), for $\varphi_{i}=0.25\left(\hat{Q}_{i}-\hat{L}_{i}\right)$, that is, 25\% of labor productivity growth, with a very small difference between firms due to the small random element introduced for the reasons noted above. ${ }^{11}$ On the other hand, the use of value data for each of the 10 firms gives a mean value of the rate of total factor productivity that is $T F P G_{i}=0.75\left(\hat{V}_{i}-\hat{L}_{i}\right)$, or $75 \%$ percent the growth of labor productivity, with a range from 80 per cent to 70 per cent. And the figure using the aggregate data (i.e., using the aggregate values of output, labor and capital) is 74 percent. The reason for the marked difference between these values and the "true" rate of technical progress is that labor's share of output in value terms is 0.75 , while the "true” output elasticity of the firms' production functions is 0.25 .

It is worth noting that TFPG in equations (2) and (3) can be written as $\operatorname{TFPG}_{t} \equiv \hat{V}_{t}-a_{t} \hat{L}_{t}-\left(1-a_{t}\right) \hat{J}_{t} \equiv a_{t} \hat{q}_{t}+\left(1-a_{t}\right) \hat{j}_{t}$, where $\hat{q}_{t}=\hat{V}_{t}-\hat{L}_{t}$ denotes the growth rate of labor productivity and $\hat{j}_{t}=\hat{V}_{t}-\hat{J}_{t}$ is the growth rate of capital productivity. This is a weighted average of the growth rates of labor and capital productivity. Therefore, it could be argued that TFPG is an aggregate measure of productivity growth. This interpretation faces, however, the problems discussed in this subsection, namely, that the figure computed is not equivalent to the true rate of technical progress.

Consequently, the use of value data produces a significantly different estimate of the rate of technical progress, compared with the "true" value obtained using physical data. Even with well-defined underlying Cobb-Douglas production functions expressed in physical terms, the use of value data as a proxy for output can give very misleading estimates of the rate of "technical progress".

\section{(iii) Increasing returns to scale and total factor productivity growth.}

11 This is because there is no growth in the physical capital-output ratio, $\varphi_{i} \equiv \alpha\left(\hat{Q}_{i}-\hat{L}_{i}\right)$ and $\alpha$, the physical output elasticity of labor, is equal to 0.25 . Hence the rate of technical progress equals one quarter of the growth of labor productivity. 
What happens if the individual firms are subject to increasing returns to scale when physical data are used? To examine this question, we first estimated the cross-firm production functions using value data when the micro production functions exhibit the same degree of increasing returns to scale. The data for the inputs in physical terms were the same as those used in the previous simulation, with the exception that now the elasticities were multiplied by 1.20 , so $\alpha^{\prime}=0.30$ and $\beta^{\prime}=0.90$. This represents a substantial degree of returns to scale and results in a value of output that is significantly larger than when constant returns to scale are imposed. The value data were calculated the same way as before, with a mark-up once again of 1/3.

Estimating the unrestricted Cobb-Douglas production function gives a result that is virtually identical to that for constant returns to scale, and reported above, except for a change in the value of the intercept. Consequently, we do not report the results here. The estimates of the putative output elasticities are once again very close to the observed (value) factor shares and sum to unity, thereby erroneously suggesting that the production process of the various firms are subject to constant returns to scale. The reason for this seemingly paradoxical result is that the calculation of value added is given by $p Q=V=(1+\mu) w L$ and as nominal wages and the level of employment are the same as before, so is the constant price measure of value added, although the price per unit is now lower (there is no inflation in the simulated data). Recall that section 3 showed that with value data, estimation of the production function would yield elasticities equal to the factor shares.

Next, we calculated the rate of technical progress and the growth of total factor productivity. For comparability with the constant returns to scale case, the growth rates of physical output, capital and labor were the same as before. The rate of technical progress was calculated using the physical data as

$$
\varphi_{i}=\hat{Q}_{i}-\alpha^{\prime} \hat{L}_{i}-\beta^{\prime} \hat{K}_{i}
$$

where $\alpha^{\prime}=1.2 \alpha$ and $\beta^{\prime}=1.2(1-\alpha)$. It can be seen that the rate of technical progress calculated using equation (10) will differ from the $0.5 \%$ in the case of constant returns 
to scale. In fact, it will be on average lower, given the larger weights of the growth of the factor inputs. The rate of technical progress, calculated using equation (10) for each firm now varies considerably across firms (for reasons of space we do not report the full results). ${ }^{12}$ The unweighted mean is (coincidentally) 0.00 per cent per annum, with a range of \pm 0.4 percentage points per annum. ${ }^{13}$

On the other hand, the growth rates of total factor productivity of the individual industries, calculated using equation (9) and value data, are again all approximately $1.5 \%$ per annum. This is because the shares of labor and capital in value terms are once again 0.75 and 0.25 , and the growth rates of $V, L$ and $J$ are the same as before. ${ }^{14}$ Thus, the use of value data can give a very misleading estimate of the true rate of technical progress. The use of value data erroneously ascribes the effect of increasing returns on increasing the efficiency of the factors of production to the rate of technical progress.

\section{(iv) Summary}

Of course, the actual figures in the simulations are arbitrary as they are dependent upon the assumed rates of growth of physical output, capital and employment. Nevertheless, we can draw some conclusions from these simulations.

- The growth of total factor productivity depends crucially on the weights attached to the growth of capital and labor. The growth accounting approach assumes that factors are paid their marginal products and hence the technologically determined output elasticities will equal the factor shares.

12 This is because while the growth rates of $Q$ and $K$ are the same between firms, employment growth rates differ and so the change in weighting causes the rate of technical change now to differ across firms.

${ }_{13}$ As we cannot sum across the physical quantities, we cannot calculate a meaningful average rate of technical progress, as the individual rates cannot be unambiguously or uniquely weighted. Nevertheless, we did calculate the unweighted mean.

$14 \quad$ With a constant mark-up of 1.33 , the shares will be always 0.75 and 0.25 , regardless of the technical conditions of production (e.g., the degree of returns to scale). 
However, when value data is used we have shown that the factor shares will always equal the putative output elasticities and both are determined by $1 /(1+\mu)$ (labor) and $\mu /(1+\mu)$ (capital), where $1+\mu$., it will be recalled, is the mark-up. The estimates of the output elasticities using value data will almost certainly differ from the true ones (always assuming that there is a welldefined micro-production function in physical terms).

- Where it is possible to compare the "true" growth rate of technical progress with the growth of total factor productivity in value terms (namely at the firm level here), the two values will probably differ markedly. In general, it is not possible to recover the physical quantities (of both output and capital) from the value data through the individual prices, and so resort is made to value data with potentially very misleading results. Where the physical data can be inferred, it can only be done at a very low level of aggregation. It requires each output and capital good to be measured separately in physical terms.

- The problems posed by the accounting identity are independent from, and in a sense more fundamental than, either the aggregation problem or the Cambridge Capital Theory Controversies. This is because the problems arise even when the latter do not pose any problems.

It should be clear by now that from the simulations that all estimations of aggregate production functions do is to approximate the NIPA accounting identity, and as such they are exercises which, although algebraically correct, stand without any theoretical foundation.

What then are we to make of Barro’s (1999, p.123) argument that an economy that experiences an increase in both its real wage and profit rates must have increased its overall level of productivity? It could be argued that TFPG $=a_{t} \hat{w}_{t}+\left(1-a_{t}\right) \hat{r}_{t}$ measures such a rate of growth of efficiency. Certainly, under these circumstances one 
can say that the economy is somewhat better off, since obviously this measure contributes positively to output growth. The point to note is that it is not possible to ascribe this unambiguously to the result of technical change the way it is done in the neoclassical model (i.e., by claiming that this idea derives from a testable model). There is no reason to assume that factor shares, i.e., the "appropriate" or theoretically justified weights according to Barro (1999, p.123), equal the output elasticities of the true aggregate production function (if it, in fact, exists), or that production is necessarily subject to constant returns to scale (although this is what the use of value data will show). The derivation is simply a tautology resulting from an identity with no behavioral assumptions or implications. The wage rate is likely to be correlated with labor productivity in value terms, and changes in the rate of profit are also likely to be associated with changes in the capital-output ratio, also measured in value terms.

Suppose, for the sake of the argument, that the factor shares are determined by the relative bargaining power of labor vis-àvis capital. Let us assume further that capital's share increases and labor's share falls due to changes in legislation relating to trade unions. Even though in physical terms the growth rates of output and inputs, and hence of technical change, remain the same by assumption, the calculation of TFPG will show a decline compared with its previous value. Hence, the concept of total factor productivity growth cannot be given purely a technological interpretation.

\section{CONCLUSIONS}

This paper has shown how the use of value data may give very misleading estimates of the true rate of technical progress, when value data is used. The simulation exercises have shown how the use of value data will give a misleading impression of the sources of growth. For example, even though the micro-production functions each exhibited increasing returns to scale with labor and capital's output elasticities taking a value of 0.3 and 0.9 , respectively, empirical estimation with value data, however, gives the traditional values of 0.75 and 0.25 . Moreover, the estimates of TFPG are very different from the true values at the industry level. 
How are then we to interpret the Solow residual, in either its primal or dual form? For it to be a seen as a uniquely determined measure of technical progress requires the assumption that the inputs and outputs of the economy (or individual industries) can be represented by an aggregate production function. This seems implausible, given the theoretical objections that have been leveled against it. As Hahn (1972, cited by Blaug, 1974, p.19) put it: "It has often been the case that a neo-classical theory has been attempted in terms of aggregate production functions and aggregates like capital. Except under absurdly unrealistic assumptions such an aggregate theory cannot be shown to follow from the proper theory and in general is therefore open to severe logical objection. ... On purely theoretical grounds there is nothing to be said in its favor. The view that that nonetheless it 'may work in practice' sounds a little bogus and in any case the onus of proof is on those who maintain this.” Recourse to empirical estimation does not shed any light on the issue, and, indeed, it is always possible to get a perfect fit to the data in a form that resembles an aggregate production function

Barro (1999) has suggested how the growth accounting approach may be adjusted to incorporate the arguments of the endogenous growth models. However, this requires the existence of a well-behaved aggregate production function. The problem is that physical data for industrial processes are not readily available and where it is, it is at a very low level of aggregation. Moreover, it is very unlikely that the simple (if not simplistic) Cobb-Douglas, or even the translog, is likely to adequately model the production processes of a modern manufacturing plant.

Solow once remarked that: "I have never thought of the macroeconomic production function as a rigorous justifiable concept. In my mind, it is either an illuminating parable, or else a mere device for handling data, to be used so long as it gives good empirical results, and to be abandoned as soon as it doesn't, or as soon as something better comes along” (Solow 1966, pp.1259-1260). Perhaps such time has arrived. On the debate about the sources of growth in East Asia, Felipe (1999) already warned against what he termed the Solow residualization of the East Asian countries, and advocated the application of a completely different methodology to understand the phenomenal growth of the NIEs (e.g., use of firm-level data). And Felipe and Fisher 
(2003, p.257) concluded their survey on the aggregation literature as follows: "Macroeconomists should pause before continuing to do applied work with no sound foundation and dedicate some time to studying other approaches to value, distribution, employment, growth, technical progress, etc., in order to understand which questions can legitimately be posed to the empirical aggregate data.” The neoclassical growth accounting exercise merely serves to reinforce these conclusions. 


\section{References:}

Barro, Robert. 1999. "Notes on Growth Accounting." Journal of Economic Growth, Vol.64, No.2 (June): 119-137.

Blaug, M. 1974. The Cambridge Revolution. Success or Failure? A Critical Analysis of Cambridge Theories of Value and Distribution. Eastbourne: Institute of Economic Affairs.

Cobb, C.W. and Douglas, Paul, H. 1928. “A Theory of Production.” American Economic Review, Vol.18, Supplement (March), Papers and Proceedings of the Fortieth Annual Meeting of the American Economic Association, (December): pp. 139-165.

Cohen, A. and G.C. Harcourt. 2003. "Whatever Happened to the Capital Controversies?” Journal of Economic Perspectives Vol. 17 (Winter): 199-214.

Douglas, Paul. 1976. "The Cobb-Douglas Production Function Once Again: Its History, Its Testing, and Some Empirical Values.” Journal of Political Economy, Vol. 85 (October): pp. 903-915.

Felipe, Jesus. 1999. "Total Factor Productivity Growth in East Asia: A Critical Survey.” The Journal of Development Studies, Vol.34, No.5 (April): 1-41.

Felipe, Jesus and Adams., F. Gerard. 2005. “A Theory Of Production. The Estimation of the Cobb-Douglas Production Function: A Retrospective View.” Eastern Economic Journal (forthcoming).

Felipe, Jesus, and Fisher, Franklin M. 2003. "Aggregation in Production Functions: What Applied Economists Should Know.” Metroeconomica, Vol.54, No.2-3 (MaySeptember): 208-262.

Felipe, Jesus, and Carsten Holz. 2001. "Why Do Aggregate Production Functions Work? Fisher's Simulations, Shaikh's Identity, and Some New Results.” International Review of Applied Economics, Vol.15, No.3 (July): 261-285.

Felipe, Jesus, and J.S.L. McCombie. 2003. "Some Methodological Problems with the Neoclassical Analysis of the East Asian Miracle.” Cambridge Journal of Economics, Vol.54, No.5 (August): 695-721.

Felipe, Jesus, and J.S.L. McCombie. 2006a. "On the Rental Price of Capital and the Profit Rate. The Perils and Pitfalls of Total Factor Productivity Growth.” Review of Political Economy, (forthcoming) 
Felipe, Jesus, and J.S.L. McCombie. 2006b. "Is a Theory of Total Factor Productivity Really Needed?” Metroeconomica, (forthcoming).

Felipe, Jesus, and J.S. L. McCombie. 2005c. "How Sound are the Foundations of the Aggregate Production Function?” Eastern Economic Journal. (forthcoming).

Felipe, Jesus, and J.S.L. McCombie. 2001. "Biased Technical Change, Growth Accounting, and the Conundrum of the East Asian Miracle.” Journal of Comparative Economics, Vol.29, No.3 (September): 542-565.

Fisher, F.M. 1971a. “Reply”, Econometrica, Vol.39, No.2 (March): 405.

Fisher, F.M.1971b. "Aggregate Production Functions and the Explanation of Wages: A Simulation Experiment", The Review of Economics and Statistics, Vol.53, No.4 (November), pp.305-325.

Fisher, F.M., Robert Solow, and J.M. Kearl. 1977. "Aggregate Production Functions: Some CES Experiments.” Review of Economic Studies, Vol.44, No.2: 305-320.

Foster, Lucia, John Haltiwanger, and Chad Syverson. 2005. "Reallocation, Firm Turnover, and Efficiency: Selection on Productivity or Profitability?” NBER Working Paper 11555.

Friedman, Milton. 1953. “The Methodology of Positive Economics.” In M. Friedman (ed.) Essays in Positive Economics. Chicago: Chicago University Press.

Hahn, F. 1972. The Share of Wages in the National Income: An Enquiry into Distribution Theory. London: Weidenfeld and Nicholson.

Hart, Peter E. 1996. "Accounting for the economic growth of firms in the UK manufacturing since 1973.” Cambridge Journal of Economics, 20: 225-242.

Hsieh, Chang-Tai. 1999. "Productivity Growth and Factor Prices in East Asia.” American Economic Review. Papers and Proceedings, Vol.89, May, No.2: 133-138.

. 2002. "What Explains the Industrial Revolution in East Asia? Evidence from Factor Markets.” American Economic Review, Vol. 92, pp.502-526.

Hulten, Charles.R. 2001. “Total Factor Productivity: A Short Biography.” in Hulten, C.R.; Dean, Edwin.R.; Harper, Michael J., (ends). New Developments in Productivity Analysis. NBER Studies in Income and Wealth, vol. 63. Chicago and London: University of Chicago Press, 2001; pp. 1-47 
Jorgenson, D.W. 1963. "Capital Theory and Investment Behavior." American Economic Review Papers and Proceedings Vol. 53 (May): 247-259.

Jorgenson, D. W., and Z. Griliches. 1967. "The Explanation of Productivity Change." Review of Economic Studies Vol. 34, No.3, (July): 249-83.

McCombie, J.S.L. 1998a. “Are There Laws of Production?’: an assessment of the early criticisms of the Cobb-Douglas production function. Review of Political Economy, Vol.10, No.2 (April): pp. 141-173.

McCombie, J.S.L. 1998b. "Rhetoric, Paradigms and the Relevance of the aggregate Production Function.” In P. Arestis (ed.), Method, Theory and Policy in Keynes. Essays in Honour of Paul Davidson, Volume III, Cheltenham, Edward Elgar.

McCombie, J.S.L. 2001. "What Does the Aggregate Production Function Show? Further Thoughts on Solow's 'Second Thoughts on Growth Theory' ”. Journal of Post Keynesian Economics, Vol. 23 No.4 pp. 589-615.

Nelson, Richard, and Howard Pack. 1999. Nelson, Richard R., and Pack, Howard, “The Asian Growth Miracle and Modern Growth Theory.” Economic Journal, Vol. 109 (July), 457: 416-436.

Phelps Brown, E.H. 1957. "The Meaning of the Fitted Cobb-Douglas Function.” Quarterly Journal of Economics, Vol. 71. November 1957, 546-60.

Prescott, Edward. 1998. "Needed: A Theory of Total Factor Productivity." International Economic Review, Vol.39, No.3 (August): 525-551.

Reder, M.W. (1943), “An Alternative Interpretation of the Cobb-Douglas Function”, Econometrica, vol.11, pp.259-264.

Shaikh, Anwar. 1980. “Laws of Production and Laws of Algebra: Humbug II.” In E. J. Nell (ed.) Growth, Profits and Property, Essays in the Revival of Political Economy, pp.80-95. Cambridge: Cambridge University Press.

Simon, H.A. 1979. "On Parsimonious Explanation of Production Relations”. Scandinavian Journal of Economics, Vol. 81, No. 4, pp. 459-474.

Solow, Robert. 1966. "Review of Capital and Growth”, American Economic Review, Vol.56, No.5 (December): 1257-1260. 
Sylos Labini, Paolo. 1995. "Why the Interpretation of the Cobb-Douglas Production Function Must be Radically Changed", Structural Change and Economic Dynamics, Vol.6: 485-504. 